\title{
Evaluation of hand anthropometric measurements and grip strength in basketball, volleyball and handball players
}

\author{
Çağatay Barut ${ }^{1}$, Pınar Demirel $^{2}$, Sibel Kıran ${ }^{3}$ \\ ${ }^{1}$ Department of Anatomy, School of Medicine, Zonguldak Karaelmas University, Zonguldak, Turkey \\ ${ }^{2}$ School of Physical Education and Sports, Dumhipinar University, Kïtabya, Turkey \\ ${ }^{3}$ Department of Public Health, School of Medicine, Zonguldak Karaelmas University, Zonguldak, Turkey
}

\begin{abstract}
Objectives: This cross-sectional study was performed to compare hand anthropometric measurements and grip strength among different sports groups.

Methods: The study group was composed of 145 basketball players, 133 volleyball players and 96 handball players aged between 9-18 years. A digital compass (Shan, $150 \mathrm{~mm}$ ) with a resolution of $0.01 \mathrm{~mm} / 0.0005$ inch was used for hand anthropometric measurements and a digital hand dynamometer (Takei) was used for grip strength measurement. During measurements values for both hands were obtained. Eight parameters were evaluated for each hand. For statistical analyses One Way ANOVA for parametric conditions and Kruskal-Wallis Variance Analyses for subgroups which have nonparametric conditions were performed. The differences within the groups were evaluated with post hoc Bonferroni adjustment.

Results: There were statistically significant differences for right and left hand width, right finger index, right hand length/height, left hand length/height values between basketball, handball and volleyball players. The differences between basketball and handball players were the reason for the aforementioned differences. There were statistically significant differences in right and left width, right and left third finger length, right and left hand grip strength values in females. These significances were caused by handball players.

Conclusion: These findings suggest that different sports could constitute different effects on hand anthropometric measurements and grip strength and sex should be considered.
\end{abstract}

Key words: hand; anthropometry; grip strength; sports

Anatomy 2008; 2: 55-59, (c) 2008 TSACA

\section{Introduction}

The human hand is unique in being free of habitual locomotor duty and devoted entirely to functions of manipulation. Its effectiveness in these activities is due to particular configuration of the bones and muscles which permits opposition of the pulp surface of the thumb to the corresponding surfaces of the other four finger tips in a firm grasp, together with a highly elaborated nerv- ous control and sensitivity of the fingers. ${ }^{1}$ Hand is a very complex structure capable of not only a multitude of motor tasks but also of relaying sensory information about the temperature, the shape and texture of objects to the brain. ${ }^{2}$

The hand does not function in isolation, and is dependent on the integrity of the shoulder and elbow complexes to allow the appropriate positioning of the hand in space to complete the desired task. ${ }^{2}$ 
Ball games require comprehensive ability including physical, technical, mental and tactical abilities. Among them physical abilities of players exert marked effects on the skills of the players themselves and the tactics of the team. For the ball games in which the use of the hand is essential, hand morphology and functional properties could be important for the performance.

The aim of this study was to evaluate the effect of different sports branches on the physical characteristics and function of the hand. Hand anthropometric measurements were performed in order to evaluate the physical characteristics of the hand, and the grip strength was chosen as the indicator of hand function. These parameters were evaluated in basketball, volleyball and handball players in which hand functions are very important for the performance of the players.

\section{Materials and Methods}

This cross-sectional study was performed with the participation of 145 basketball, 133 volleyball and 96 handball players aged between $9-18$ years. All of the participants were players of the school teams which have degrees in provincial tournaments.

Exclusion criteria were set upon our knowledge of some genetic, psychological, neurological or chronic diseases affecting hand function and anthropometric characteristics. ${ }^{3,4}$ Diseased or disabled persons were excluded from the study according to the mentioned criteria. Informed consents of all participants were obtained. The Ethics Committee of Karaelmas University also endorsed its approval for the study.

\section{Anthropometric measurements}

A digital compass (Shan $150 \mathrm{~mm}$ ) with a resolution of $0.01 \mathrm{~mm} / 0.005$ inch was used for anthropometric measurements. Measurements were taken from the palmar side with digits fully stretched touching on a flat, hard surface and the 2 nd to 5 th digit adducted and the thumb slightly extended. ${ }^{5}$

For each hand, 7 parameters related with hand dimensions and ratios were evaluated. Hand width, hand length, 3rd digit length and body height were measured with the method stated by Pheasent. ${ }^{6}$ The hand length/body height ratio, the shape index which determines hand shape, the digit index which determines grasping capability and palmar length/width ratio which determines palmar type without the digits were also assessed.

Palmar length: The palmar length defined as the distance between the midpoint of the distal wrist crease and the midpoint of the proximal digit crease, was calculated according to the formula hand length minus $3 \mathrm{rd}$ digit length. ${ }^{4,5}$

Shape index (length-width index, hand index): Hand width x 100/Hand length.

Digit index (phalangeal index): 3 rd digit length $x$ 100/hand length.,

Palmar length/width ratio: Palmar length/Palmar width $\left(\right.$ Palmar width $=$ Hand width) ${ }^{4,5}$

Hand length/height ratio: Hand length/Body height. ${ }^{5}$

Body weight was measured using a standard scale with light clothing on and without any footwear. Height was measured with the individual in upright position in front of a wall looking ahead and heels touching one another.

\section{Grip strength}

A digital hand dynamometer (Takei) was used to measure the grip strength. The participant sat on a chair with the elbow flexed at 900 and the forearm in semipronation lying on an arm rest. The participants were asked to squeeze the dynamometer three times with each hand. There was a one minute resting period between each squeeze in order to overcome fatigue. The mean value of three squeezes was taken into account. ${ }^{8}$

\section{Data analysis}

Statistical analyses were performed with SPSS for windows Release 11.01. Statistical comparisons of subgroups for parametric and non-parametric conditions were performed using Analyses of Variance (One Way ANOVA) and Kruskal-Wallis Variance Analyses respectively. The differences within the groups were evaluated with post hoc Bonferroni adjustment. 


\section{Results}

There were statistically significant differences in right and left hand shape indices, right and left hand length/ height ratio values between male basketball, volleyball and handball players. Difference between basketball and handball groups was the reason of the significance (Table 1).

There were significant differences in right and left hand width, right and left hand length, right and left 3rd finger length, right and left grip strength values between female basketball, volleyball and handball players. Handball group was the reason of the significance (Table 2).

There were significant differences in right and left hand width, right digit index, right and left hand length/height ratio values between basketball, volleyball and handball players when all individuals were considered. When right and left hand width values were considered the difference between the basketball and handball groups caused the significance. When right and left hand length/height ratio values were considered the difference between the volleyball and handball groups caused the significance (Table 3).

\section{Discussion}

Physical activities and sports have an important role not only in proper growth and maturation of the child but may also delay the physical frazzle which might occur with the advance of age.'

There are various studies concerning the effects of sports on anthropometric measurements and physical status of the human body. ${ }^{9-12}$ In this study the effect of three different sports branches on the hand morphology and function was evaluated.

In the study of Colak in which physiological and anthropometric parameters were investigated in males aged between $10-15$ years it was stated that there was a significant difference between the groups when arm length and whole upper extremity length was considered and volleyball group was the reason for those differences. Also when the forearm length was considered the difference between the groups was not statistically significant. ' Although hand parameters were not investigated in the study of Çolak, he suggested that most of the differences were caused by the volleyball playing group.

Table 1

Comparison of hand parameters of male basketball, volleyball and handball players

\begin{tabular}{|c|c|c|c|}
\hline & $\begin{array}{l}\text { Basketball } \\
\text { mean (sd) } \\
\quad n=85\end{array}$ & $\begin{array}{c}\text { Volleyball } \\
\text { mean (sd) } \\
n=70\end{array}$ & $\begin{array}{c}\text { Handball } \\
\text { mean (sd) } \\
n=81\end{array}$ \\
\hline Right hand width (mm) & $77.80(8.13)$ & $80.17(7.64)$ & $80.09(9.20)$ \\
\hline Left hand width (mm) & $76.85(7.77)$ & $79.60(7.43)$ & 79.05 (8.99) \\
\hline Right hand length (mm) & $172.87(17.73)$ & $176.77(18.42)$ & $174.54(19.83)$ \\
\hline Left hand length (mm) & $173.84(18.11)$ & $177.53(18.13)$ & $175.21(20.70)$ \\
\hline Right 3rd digit length (mm) & $74.45(8.42)$ & $75.75(9.09)$ & $74.47(9.37)$ \\
\hline Left 3rd digit length (mm) & $74.72(8.13)$ & $76.17(8.58)$ & $74.88(9.72)$ \\
\hline Right shape index* & $45.01(2.17)$ & $45.42(2.14)$ & $45.89(1.73)$ \\
\hline Left shape index* & $44.32(2.08)$ & $45.08(2.33)$ & $45.12(1.73)$ \\
\hline Right digit index & $43.03(1.53)$ & $42.88(1.23)$ & $42.60(1.12)$ \\
\hline Left digit index & $43.03(1.44)$ & $42.92(1.67)$ & $42.68(1.13)$ \\
\hline Right palmar length/width ratio & $1.26(0.08)$ & $1.25(0.06)$ & $1.25(0.05)$ \\
\hline Left palmar length/width ratio & $1.29(0.07)$ & $1.27(0.07)$ & $1.27(0.06)$ \\
\hline Right hand length/height ratio* & $0.108(0.004)$ & $0.109(0.004)$ & $0.111(0.004)$ \\
\hline Left hand length/ height ratio* & $0.109(0.004)$ & $0.110(0.004)$ & $0.111(0.005)$ \\
\hline Right grip strength (kg) & $23.07(10.32)$ & $24.46(10.51)$ & $22.89(10.84)$ \\
\hline Left grip strength (kg) & $22.09(9.83)$ & $24.35(10.38)$ & $22.12(10.52)$ \\
\hline
\end{tabular}

Analyses of Variance, ${ }^{*} p<0.05$ 
Table 2

Comparison of hand parameters of female basketball, volleyball and handball players

\begin{tabular}{lccc}
\hline & $\begin{array}{c}\text { Basketball } \\
\text { mean (sd) } \\
\mathbf{n = 6 0}\end{array}$ & $\begin{array}{c}\text { Volleyball } \\
\text { mean (sd) } \\
\mathbf{n}=63\end{array}$ & $\begin{array}{c}\text { Handball } \\
\text { mean (sd) } \\
\mathbf{n}=\mathbf{1 5}\end{array}$ \\
\hline Right hand width $(\mathrm{mm})^{*}$ & $75.06(5.67)$ & $76.41(4.15)$ & $78.92(3.21)$ \\
Left hand width $(\mathrm{mm})^{*}$ & $73.69(5.75)$ & $74.93(3.93)$ & $77.82(2.85)$ \\
Right hand length $(\mathrm{mm})^{*}$ & $166.98(12.17)$ & $170.97(10.25)$ & $179.00(8.22)$ \\
Left hand length $(\mathrm{mm})^{*}$ & $167.94(12.70)$ & $171.42(10.67)$ & $179.10(7.79)$ \\
Right 3rd digit length $(\mathrm{mm})^{*}$ & $72.53(5.99)$ & $73.92(5.31)$ & $77.82(3.63)$ \\
Left 3rd digit length $(\mathrm{mm})^{*}$ & $72.65(6.18)$ & $74.05(5.43)$ & $77.65(2.85)$ \\
Right shape index & $44.98(2.03)$ & $44.75(2.00)$ & $44.27(1.98)$ \\
Left shape index & $44.02(2.02)$ & $43.76(2.00)$ & $43.50(2.01)$ \\
Right digit index & $43.41(1.19)$ & $43.26(1.20)$ & $43.45(1.18)$ \\
Left digit index & $43.26(1.46)$ & $43.62(2.35)$ & $43.37(1.09)$ \\
Right palmar length/width ratio & $1.26(0.06)$ & $1.27(0.06)$ & $1.28(0.06)$ \\
Left palmar length/width ratio & $1.29(0.07)$ & $1.30(0.06)$ & $1.30(0.07)$ \\
Right hand length/height ratio & $0.107(0.004)$ & $0.109(0.005)$ & $0.110(0.004)$ \\
Left hand length/height ratio & $0.108(0.004)$ & $0.109(0.005)$ & $0.110(0.004)$ \\
Right grip strength $(\mathrm{kg})^{*}$ & $18.23(4.34)$ & $18.89(4.00)$ & $23.17(3.20)$ \\
Left grip strength $(\mathrm{kg})^{*}$ & $18.15(4.10)$ & $18.76(4.25)$ & $22.89(3.12)$ \\
\hline
\end{tabular}

Kruskal-Wallis Variance Analyses, ${ }^{*} p<0.05$

Table 3

Comparison of hand parameters of all players

\begin{tabular}{|c|c|c|c|}
\hline & $\begin{array}{c}\text { Basketball } \\
\text { mean (sd) } \\
n=145\end{array}$ & $\begin{array}{c}\text { Volleyball } \\
\text { mean (sd) } \\
n=133\end{array}$ & $\begin{array}{c}\text { Handball } \\
\text { mean (sd) } \\
n=96\end{array}$ \\
\hline Right hand width $(\mathrm{mm})^{*}$ & $76.67(7.32)$ & $78.39(6.49)$ & $79.91(8.54)$ \\
\hline Left hand width $(\mathrm{mm})^{*}$ & $75.55(7.15)$ & $77.39(6.45)$ & $78.86(8.34)$ \\
\hline Right hand length $(\mathrm{mm})$ & $170.43(15.89)$ & $174.02(15.34)$ & $175.24(18.54)$ \\
\hline Left hand length (mm) & $171.40(16.31)$ & $174.63(15.32)$ & $175.81(19.28)$ \\
\hline Right 3rd digit length (mm) & $73.65(7.54)$ & $74.88(7.57)$ & $74.99(8.80)$ \\
\hline Left 3rd digit length (mm) & $73.87(7.43)$ & $75.17(7.31)$ & $75.31(9.05)$ \\
\hline Right shape index & $45.00(2.10)$ & $45.10(2.10)$ & $45.63(1.86)$ \\
\hline Left shape index & $44.20(2.05)$ & $44.45(2.27)$ & $44.87(1.86)$ \\
\hline Right digit index* & $43.19(1.41)$ & $43.06(1.22)$ & $42.73(1.17)$ \\
\hline Left digit index & $43.13(1.45)$ & $43.25(2.05)$ & $42.79(1.14)$ \\
\hline Right palmar length/width ratio & $1.26(0.07)$ & $1.26(0.06)$ & $1.25(0.05)$ \\
\hline Left palmar length/width ratio & $1.29(0.07)$ & $1.28(0.07)$ & $1.27(0.06)$ \\
\hline Right hand length/body height ratio* & $0.108(0.004)$ & $0.109(0.005)$ & $0.110(0.004)$ \\
\hline Left hand length/body height ratio* & $0.108(0.004)$ & $0.110(0.005)$ & $0.111(0.005)$ \\
\hline Right grip strength $(\mathrm{kg})$ & $21.07(8.69)$ & $21.82(8.55)$ & $22.94(10.02)$ \\
\hline Left grip strength $(\mathrm{kg})$ & $20.46(8.19)$ & $21.70(8.52)$ & $22.24(9.73)$ \\
\hline
\end{tabular}

Analyses of Variance, ${ }^{*} p<0.05$

When the results obtained from the males were considered there were only significant differences for right and left hand shape indices, right and left hand length/body height ratios between basketball, volleyball and handball players. The difference between basketball and handball groups was the reason for these results (Table 1). When the results obtained from the females were considered there were only significant differences for hand width, hand length, 3rd finger length, and grip strength values between basketball, volleyball and hand- 
ball players. The handball group was the reason for the significance (Table 2). When the results obtained from all participants were considered there were only significant differences for hand width, hand length/height ratio for both hands, right digit index values between basketball, volleyball and handball players. Difference between volleyball and handball groups was the reason of the significance (Table 3).

In the study of Colak ${ }^{9}$ the greatest value for grip strength for both hands were obtained from the football group but the differences were not significant. In our study there were no significant differences between the groups when males and the whole study group were considered for the hand grip values. Volleyball players had the greatest grip strength among males (Table 1). The handball players had the greatest grip strength when the whole study group was considered (Table 3). Hand grip strength of female handball players was significantly higher than the other females (Table 2).

In this study it could be suggested that the reason for most of the differences was handball group, as handball requires more efficacious usage of hands.

\section{References}

1. Markze MW. Origin of the human hand. Am 7 Phys Antbropol 1971; 34: 61-84.
2. BlairVA. Hand function. In: Durward BR, Baer GD, Rowe PJ, eds. Functional Human Movement. Oxford: Butterworth-Heinemann; 2002. p. 160-79.

3. Malina RM, Buschang PH. Anthropometric asymmetry in normal and mentally retarded males. Ann Hum Biol 1984; 11: 515-31.

4. Brill T, Stier S. Hand parameter differences between psychiatric patients and normal controls: a preliminary evaluation. Isr 7 Psychiatry Relat Sci 1999; 36: 105-14.

5. Kulaksiz G, Gozil R. The effect of hand preference on hand anthropometric measurements in healthy individuals. Ann Anat 2002; 184: 257-65.

6. Pheasent S. Anthropometrics: An Introduction. United Kingdom: British Standards Institution; 1990. p. 18-9.

7. Napier J. Hands. New Jersey: Princeton University Press; 1990. p. 25-7, 124.

8. Hager-Ross C, Rosblad B. Norms of grip strength in children aged 4-16 years. Acta Paediatr 2002; 91: 617-25.

9. Colak H. Investigate physical fitness and physiological parameters in male players between 10-15 ages of volleyball, basketball and football in the district of Giresun (Master of Science Thesis). Trabzon: Black Sea Technical University, 1995.

10. Lozovina V, Pavicic L. Anthropometric changes in elite male water polo players: Survey in 1980 and 1995. Croat Med F 2004; 45 : 202-5.

11. Tutkun E. The evaluation of anthropometry measurement and appropriateness of their branch on athlete students at university (Master of Science Thesis). Samsun: Ondokuz Mayis University, 1996.

12. Albayrak E. Analyzing of the motoric-test results and anthropometric structures of the female and male subjects who are taking place in the school teams of the Marmara University (Master of Science Thesis). Istanbul: Marmara University, 1991.

\footnotetext{
Correspondence to: Çağatay Barut, MD

Zonguldak Karaelmas University, School of Medicine, Department of Anatomy

Zonguldak 67600 Turkey

Phone: +90 53246384 71; Fax: +90 3722610264

e-mail: cagbarut@yahoo.com

Conflict of interest statement: No conflicts declared.
} 